\title{
How Dutch Health-care Neglects Super-diversity
}

\author{
Carl Hermann Dino Steinmetz \\ Expats \& Immigrants Besloten Vennootschap, Amsterdam, Netherlands
}

\section{Email address:}

carl@expats-immigrants.com

\section{To cite this article:}

Carl Hermann Dino Steinmetz. How Dutch Health-care Neglects Super-diversity. Humanities and Social Sciences.

Vol. 7, No. 4, 2019, pp. 125-131. doi: 10.11648/j.hss.20190704.11

Received: June 19, 2019; Accepted: July 18, 2019; Published: July 31, 2019

\begin{abstract}
This article is about super-diverse 'healthcare. According to the Dutch 'Centraal Bureau voor de Statistiek (CBS)' $23.12 \%$ of the Dutch population comes from a country other than the Netherlands [1]. Large groups of immigrants in the Netherlands are now Indonesian, Surinamese, Turkish, Moroccan and Polish. The CBS is concerned about the (physical and mental) health of non-Western immigrants in comparison to the original Dutch [1]. In this article a proposal is made for the reorganization of psychological health care that does justice to our super-diverse society. The building blocks of this proposal come from legislation, international and national guidelines, transcultural psychiatry, and the results of scientific and practical research in healthcare. A prominent place has been given in this proposal for the concepts of 'ethnic matching' and 'all-inclusive multiculturalism' in the workplace. All-inclusive multiculturalism is about the necessity to introduce just and tolerant social super-diversity in the workplace.
\end{abstract}

Keywords: Multilingualism, Super Diverse Healthcare, Disease Narratives, Cultural Explanation, Holism, Collectivism

\section{Need to Change}

A super-diverse multilingual community in 'the New World' places new demands on all its residents, institutions and companies. That which takes place far away in motherlands of immigrants, refugees and expats, such as ebola, cholera, new Asian flu variants, stress epidemics, hunger, war and genocide, influences super-diverse societies in Western cities where people from all over the world live close together and have multiple interdependencies, is suddenly very close. Immigrants, refugees and expats bring cultural explanations for illness and sickness from their mother countries. These changes are in need of recognition by super-diverse health care in the Western world. These 'new' citizens of the New World take spirit, body and collectivism (e.g. ancestors, spirits and gods, cosmos and nature) with them that have been sculpted in a non-Western sociodemographic-geographical-subcultural environment. Anchoring these illness contexts might be called holistic [2]. Holism is beautifully worded in African philosophy Ubuntu with the saying: "Someone with Ubuntu is open to and accessible to others, devotes himself to others, does not feel threatened by the ability of others because she/he draws enough self-confidence from knowing being part of a larger whole and shrinking when others are humiliated or when others are tortured or suppressed "I am because we are" and "become human through others [3]." These super-diverse influences can, in addition to cultural enrichment and innovation, also lead to friction due to different views on morality, desired behaviour and habits.

\section{Fair and Equitable Treatment in Super-Diverse Healthcare and Multilingualism}

Fair and equitable healthcare are central in super-diverse western cities. After all, equality of opportunity is a right and not a fluke. The British National Health Service has guaranteed this right in a number of principles [4]: "care must be accessible to everyone (avoid confusing administrative barriers and anticipate that formal documents are not always in order), access to care must be based on clinical need and not on affordability (not being able to register with a general practitioner leads to avoidance of care), aim for the highest standards of professionalism, organize care so that the patient is central, organize partners (sharing information can be risky for family members in a motherland and can cause deportation anxiety. Care 
avoidance is seen as a better option), create as much value as possible for the taxpayer (reduce vulnerabilities and prevent abuse) and be accountable (a lot of stress is hidden or not being investigated. Give marginalized people and their experiences a voice)." Furthermore, descale the human- and paper bureaucracy in healthcare [5]. Patients, including immigrants, refugees and expats, experience conversations in healthcare as ruminations, every subsequent professional caregiver does not know what happened in the steps before they got involved. The care has been parcelled out by assembly line views from the industrial era. The human scale has disappeared.

Fair and just healthcare are also a concern for the European Union as a whole. An international treaty on Economic, Social and Cultural Rights was adopted by the UN General Assembly in 1966 and ratified by more than 150 countries (including the Netherlands) [6], which states that: "The States Parties to this Convention, recognize the right of everyone to enjoy the highest attainable standard of physical and mental health (Article 12 (1)), and promise to create conditions that guarantee all medical care in the event of illness (Article 12 (2)). In 2000, the World Health Organization strengthened the foregoing by prohibiting discrimination in access to healthcare, as well as resources and rights based on race, colour, gender, and language, reflecting the Charter of Fundamental Rights of the European Union (2000), which explicitly prohibits discrimination for any reason whatsoever, including language (Article 21)."

Rillof states: "that the world has evolved into a superdiverse society, and that this situation will not change [6]. Communication between service providers and patients, which is by definition multilingual, have to be addressed. A 'WE' approach is needed to achieve active togetherness." Multicultural education estimates that more than 100 languages are spoken in the Randstad. Apps, such as Go Translate, recognize multilingualism in healthcare (interpreters in the Netherlands are no longer reimbursed). The Netherlands has replaced registered translators by translanguage children who interpret for their family in healthcare centres. These children live in an "interspace", where they translate information from one party for the other and vice versa [7]. This competence is required in the 'New World', with all the dangers this entails because these children are no longer seen as children but as adults. In this gap they can come into contact with information that is not intended for their ears, as mother still has a few weeks to live.

This article is about super-diverse healthcare and the demands that healthcare institutions can make by superdiverse multilingual communities in Western cities.

\section{Super-Diverse Healthcare: The Law of Large Numbers}

Super-diverse healthcare is a must in the Netherlands. The numerical ratio of immigrants, refugees and expats to Dutch people in the Netherlands supports this statement. The Dutch population consists of $23 \%$ immigrants: "less than half of these immigrants were born in the Netherlands and belong to the second generation [1]." Table 1 shows an overview of various Dutch population groups to first and second generation [1].

Table 1. Population groups in the Netherlands by origin, first and second generation, on 1 January 2018 according to [1].

\begin{tabular}{llll}
\hline Origin & Dutch & First generation & Second generation \\
\hline Total (17.181.084) & & & \\
Original Dutch & 13.209 .200 & 191.500 & 212.900 \\
Non-Western & & & \\
Turkish & & 169.000 & 227.500 \\
Moroccan & 176.400 & 175.300 \\
Surinamese & 84.500 & 72.600 \\
Antillean & 621.400 & 688.300 \\
Subtotal non-Western & & 9.000 \\
Refugees & 81.800 & 12.800 \\
Syrian & 43.900 & 10.100 \\
Iraqi & 32.300 & 31.900 \\
Iranian & 158.000 & 260.700 \\
Subtotal refugees & & 248.800 \\
Western & & 100.900 & 38.100 \\
Indonesian & 105.400 & 73.200 \\
German & 135.000 & 720.800 \\
Polish & 45.500 & 1.441 .000 \\
Belgian & 386.800 & \\
Subtotal Western & 1.166 .200 & \\
$\quad$ Total & &
\end{tabular}

Table 1 lacks 923,684 people $(16,257,400$ people compared to $17,181,084$ people). According to CBS, "just over half of the inhabitants of Amsterdam, Rotterdam and The Hague have an immigration background, and a third in Utrecht [1]. The second generation of immigrants live in large cities less often than the first generation. Residents from Eastern European countries that recently joined the European Union, compared to the four largest non-Western immigrant groups, live more spread across the Netherlands, more often in areas with a lot of agricultural activity." These 
CBS data legitimize super-diverse healthcare in Amsterdam, Rotterdam, The Hague and Utrecht [1].

\section{Health and the Need for Super-Diverse Healthcare}

"The health of people with a Dutch background is generally better than that of people with a non-Western immigration background. People with a non-Western background have higher health care costs and experience their own health less often as (very) good [1]." These conclusions are based on a survey about health, physical illnesses, the use of medication and health costs.

"Of the 12 to 65 year old's, $64 \%$ of Moroccans experience their health as (very) good, compared to $83 \%$ of people without an immigrant background [1]. This result is remarkable because people with a Moroccan immigration background are on average younger than people without an immigration background, and young people are on average more positive about their health than the elderly [1]."

"Turks, Moroccans, Surinamese and Antilleans of the first generation clearly experience their own health as (very) good less often than the second generation. The difference between the generations is greatest for Moroccans and Turks [1]."

\subsection{Smoking, Obesity, Diabetes, and Antipsychotic}

Attention was paid to smoking, obesity, and diabetes [1]. "The first generation of Turks smoke the most (35\%), and people with a Turkish, Moroccan, Surinamese or Antillean immigrant background are more often overweight than people without an immigrant background. Antilleans (22\%) are the front runners with serious overweight. Furthermore, people with an immigrant background use diabetes more often (insulin or other blood glucose-lowering medicine) than people with a Dutch background. For people with a Surinamese background, the percentage of people $(9 \%)$ who receive medicine for diabetes is the largest. However, when immigration groups are compared by age category, people with a Moroccan background are most often given antidiabetes medicine."

\subsection{Healthcare Costs}

"The health of older people is declining and the costs of care are rising [1]. This applies to people with a Dutch as well as an immigration background. For each age group in 2016, the healthcare costs of men and women with a nonWestern background were higher than those of people with a Dutch or other Western background. For Antillean men, the average mental healthcare costs per person in 2016 (€387) were twice that of men with a Dutch background $(€ 185)$. Mental health costs were also relatively high for Surinamese and Moroccan men, at $€ 355$ and $€ 315$ per person, respectively. For men with a Turkish or other non-Western background, the costs were 16 and 18 percent higher, respectively, than for men with a Dutch background. With regard to costs for medicines, the differences between the non-Western groups are smaller. Men with a non-Western background had the highest medication costs with an average of €280."

\subsection{Possible Solutions When Improving Super-Diverse Healthcare}

These conclusions about the health of 'old' and 'new' immigrants compared to the original Dutch are worrying [1]. CBS does not provide an explanation [1]. Speculation about these differences suggests two options. First, the Amsterdam GGD (preventive healthcare office) reports that it is unable to reach immigrants, refugees and expats with preventive programs [5]. In short, the lack of preventive information is a possible explanation. This is in line with Aslan's randomized trial research where Afro-American patients are linked to either a black or white doctor with better results if the match was with a black doctor because advice about prevention was followed more often when the doctor was black. This match resulted in a 19\% reduction in the black-white male cardiovascular mortality gap and an $8 \%$ decline in the blackwhite male life expectancy gap [8]." A second option is exclusion and discrimination of immigrants, refugees, expats and Muslims, which, according to [9], yields to short-term psychoses. Accordingly is the Dutch fact that "the perception of non-Muslims towards Muslims and vice versa is not positive [10]. This image formation stands in the way of contact and the willingness to become acquainted with each other's ideas [10]."

\section{Culturally Defined Healthcare}

Super-diverse healthcare should transcends the existing categorizations of immigrants, refugees and expats. In conversations and publications about immigrants, refugees and expats, the emphasis is mainly on number of people, deportation, skin colour, ethnic origin, religion, shaking hands or not, body-covering clothing and headdress. This focus removes our view of reality. A concrete example of this phenomenon is the investigation that undermines the sense hierarchy hypothesis of Aristotle that "the sense sight occupies the largest space in the brain and the sense smell the least, as if the senses in our brains are hierarchically ordered starting with sight, sound, touch, taste and finally smell. This international study shows that languages and talking about sensory perceptions are largely culturally determined. In the Malian language Dogul Dom and the Ghanaian language Siwu, people easily speak about touch (place three in the list of Aristotle), about how something feels [11]. In eleven of the twenty languages studied, people spoke easily about taste (place four in Aristotle's list). There is even a language in which people talk easier about scent than about all other types of sensory perception: the Umpila, spoken by Australian hunter-gatherers [12]."

Illness-stories highlight a tip of the veil of super-diverse 
healthcare, a veil that envelops the world of super-diverse psychiatry with Cultural Concepts of Distress. Part of this is cultural explanation, destiny and morality. Through Cultural Concepts of Distress, psychiatry sticks DSM-terminology on stress languages of non-Western peoples. The western world has its own stress language, such as depression. The Western world considers health based on dualism (Descartes ${ }^{1}$ ) in which mind and body are separate entities. The non-Western world, on the other hand, considers health based on holism (the whole is greater than the sum of all interdependent parts of a whole) and balances (such as cold and hot, Qi, Winti Pappa and Mamma). India for example has a Hindu theory about the seven juices that represent (great) grandparents, ancestors (deceased or became ghosts), gods, universe, cosmos and nature. A person can get 'sick' (physically and/or mentally) if the ancestors are not treated with respect. The disease is then the result of the seven juices that have become unbalanced.

Some Western countries are experimenting with treatments that use both non-Western and Western insights. In Canada healers and psychoanalysts work together in ethno-psychoanalytic treatments [13]. Healers use in their work the cultural explanation of patient and extended family [13]. In France (Marie-Rose Mora) the extended family is involved in the treatment. Furthermore, the West started to present research in which mind/brain and body are presented as a unit. An example is the Dutch memorandum 'Risk of injury during long-term deportation of the children' [14] that explains that that years of continuous stress of refugee children who may be deported from the Netherlands, is harmful to their brains. Literally these researchers say: "Children suffering from chronic stress have an increased risk of losing gray (the brain areas)- and white matter (the connections) in the brain, which has a harmful influence on the social, emotional and cognitive development of children."

\section{Super-Diverse Healthcare: Guidelines for Practice}

Transcultural healthcare (culturally aware and sensitive) means: "working on consciously and sensibly coping with the culture of the various immigrants, refugees and expat groups in mental healthcare with its many subcultures and layers of granularity. Culture also requires exploring power relations and is important for every person regardless of origin and ethnic, religious or cultural heritage. Cultural issues are 'normally' given a low priority in the provision of healthcare [15]."

Apart from a better therapeutic relation, realization of culture-conscious and sensitive healthcare should also imply all-inclusive multiculturalism for mental health organizations. "All-inclusive multiculturalism helps organizations overcome the limitations of colour blindness

1 https://en.wikipedia.org/wiki/Mind\%E2\%80\%93body_dualism and multicultural ideology by promoting feelings of ethnic togetherness among staff through positive organizational change [16]." In line with the aforementioned recommendations, the Dutch Mental Health developed a generic diversity module (Akwa, Alliance Quality of Mental Healthcare, 2018) [16]. This generic diversity module focuses on dealing with ethnic and cultural diversity. This module is important in treatment relationships where patients have a cultural and ethnic background that differs from care professionals (and vice versa), or where knowledge about the cultural or immigration background is important to provide good care. This module can also be used in somatic healthcare, especially when it comes to treatment of patients and extended family and the communication between doctor, psychiatrist, psychologist, nurse and social worker with patients. After all, somatic super-diverse healthcare, is more than learning tips and tricks [17] based on normative views (cultural bias).

The suggestions below elaborates super-diverse healthcare in practical guidelines $[15,18]$. These guidelines are based on practical and scientific knowledge that develop continuously. These guidelines apply to the first contact with a patient and extended family up to and including aftercare. To that end, the American Psychological Association has developed multicultural guidelines for treating patients [19]:

1. "Promote the awareness that identity and selfdefinition are fluid, complex and dynamic.

2. Recognize that care providers also suffer from cultural bias, prejudices and formulations that arise from poor knowledge of the other.

3. Recognize that multilingualism, and knowledge of the extended family, tribe, community and culture are necessary.

4. Be aware of the social, economic and physical world of patients.

5. Acquire knowledge about the history of power, oppression and privileges (including (neo) colonization, refugees and immigration history and the residence in a new fatherland).

6. Promote (sub) cultural sensitive interventions.

7. Encourage critical reflection on your own assumptions and practices from an international context.

8. Acquire knowledge about culturally determined stages of development from infants to adults, such as those in Ubuntu and collectivism.

9. Perform education, research, coaching, intervision and supervision in a cultural sensitive way.

Work with sources of resilience, strength and forgiveness on individuals, large families, groups, community and organization, also to ensure that traumas decrease sociocultural."

These super-diverse guidelines are further detailed below. Complicated in Dutch healthcare is the fragmentation of care, not the patient is central but the discipline of the careprovider and the 'label' defining whether the request for care has begun or has become clear. The general practitioner (GP) in the Netherlands is leading in all phases of the care process. 
Getting acquainted. Getting acquainted is meeting and connecting, not as a 'curious little monkey' but as humans connected to each other through their histories and narratives. Getting acquainted is also figuring out who the key figures of the patient are and what their commitment consists of. Then too, forgiveness might be raised especially if there are psychotrauma's [2].

Getting acquainted starts with the website of the general practitioners office. The professional background, familial and personal history of general practitioner, and medical- and secretarial staff can be sketched for every person on the website in images and languages of patients with icons and short video's. Immigrants, refugees and expats should get the impression that these professionals are Our Kind of People. That might lower the threshold to come and continue to do so.

General practitioner. A general practitioner in the Netherlands establishes contact between patient and a 'general practitioner care support provider (POH-Mental Health and POH-Somatic)' who might come to visit a patient and extended family at home and provide information about the clinical issues, guidance on medication use, information about lifestyle and eating patrons.

Psychoeducation and general practitioner. Patients and extended family (especially key figures) could learn more about health, healthy living and healthy food in a general practitioners office. This is possible if an educational library is set up for this purpose, with a $\mathrm{POH}$ as coach, showing a patient the way between video clips, virtual reality and the accompanying explanations. These videos and virtual reality are a connection between the world of medicine and illness and the world of immigrants, refugees and expats. This visual material can be linked to insights from positive psychology, while walking the path from getting acquainted to treatment and evaluation.

Genogram. A genogram can be performed by the $\mathrm{POH}$ at the general practitioners office. A genogram (also known as a McGoldrick-Gerson study, a Lapidus scheme or a family diagram) is a visual representation of someone's (extended) family relationships, medical-somatic, historical and psychological history. Through a traditional family tree the user can visualize hereditary patterns, psychological and physical factors of all known members of the family. A genogram $^{2}$ is used to identify repetitive patterns. Example: when Achmed made a genogram of his grandfather, he discovered that his extended family struggled for generations with lung diseases and cancer, with loss and mourning. In this four-generation family, one cigarette is lit with the other. Because of this insight, Achmed started to inform his grandfather about the physical and psychological consequences of smoking.

Via a genogram, information can also be obtained about key figures of the patient and why they take that position in a patient's life? Additional information can be collected about sickness hypotheses, and a cultural explanation of the

2 https://www.genopro.com/genogram/ patient's sickness can be discussed. The treatment plan should then be discussed with patient and key figures. At last approval for the approach in the treatment plan can also be requested.

Lifeline. Filling in a lifeline can be done with the $\mathrm{POH}$. The key question is: describe your life in chronological order with the help of a timeline and data with catchwords, and indicate which people and events have changed your life. Above the timeline positive events in life, such as having a child, can be written down. Below the timeline there is room for negative events, such as the loss of parents. Negative events however can also enrich us as humans. The holy books tell us that the only thing 'that counts' is 'how we deal/cope with negative events'. Sub-questions for this lifeline are:

1. From your 4 th year of life until now.

2. What are highs and lows?

3. What are junctions or turning points in your life?

4. Who or what were important in this regard?

5. Which decisions (positive or negative) had a long or short-term effect?

6. What thoughts, feelings, and behaviours preceded the nodes in your life?

7. Explicitly mention nodes that have had a long-term effect in a negative sense ((neo) colonization, flights, immigration, unemployment, divorce, death, etc.). The suffering that you have experienced makes you human.

8. Where are you now? (age, life situation, in work and family etc.)

$\mathrm{A} \mathrm{POH}$, together with the patient, reviews the outcomes via the question of what stands out in this lifeline. A possible conclusion is: 'my life looks like the waves in the sea, it usually ripples and sometimes it is a flood. If it is rippling, I have to spend more time with my grandfather, my ancestors, the spirits, the gods, nature and the cosmos, because then the waves may be less high when the tide comes.'

The cultural explanation of the disease. Cultural Concepts for Distress in the DSM-5 are indications of how persons of different cultural groups suffer, experience problems, notice disruptive thoughts and emotions, experience, understand and communicate about them. Underlying these concepts are cultural idioms (stress words), cultural-bound syndromes (clusters of symptoms and attributions in specific cultural groups that are locally-geographically recognized as coherent patterns of experience) and cultural explanations for distress (labels, attributions, or characteristics of an explanatory model that is an indication of a culturally recognized meaning or aetiology associated with symptoms, illness or distress). This umbrella of terms can also be called stress language [20]. Non-Western stress languages might also be relevant for somatic complaints. This conceptual apparatus -the so called stress language- must be questioned in such a way that it fits in with a sickness story, with the cultural explanation as the common thread. The cultural explanation can be understood as a guideline for treatment of patients and extended family or key figures by healers together with general practitioners, doctors, psychologists, nurses and social workers. 
Super-diverse work. Lago shows that more power is given to 'WHITE' care-providers by immigrants, refugees and expats than to 'BLACK' care-providers (see also the documentary of Sunny Bergman (White is also a Colour) and the Implicit Association Test) [21, pp. 94]. Reviews show (Farkhondeh et al.) that ethnic matching is preferred [21, 21, pp. 75]. Culture and language are more or less the same. An ethnic match increases the chance of an effective and empathetic therapeutic relationship with fewer no-shows and dropouts. In addition, Lago asks care professionals to review patients' experiences with racism, discrimination, microaggression and oppression, so that these experiences can be cognitively restructured [21]. This should also be applied to such experiences that occur consciously, incompetently and unknowingly in the treatment (Alleye, pp. 117, [21]). Finally, a care professional should furthermore delve per (sub) culture into history, flora and fauna, the origin of that culture, solidarity with the extended family, ancestors (living and deceased), children not yet born and embedding in cosmos and nature [21]. Refugees and undocumented migrants also deserve this attention. That is already possible by searching the origin of the extended family together with patient via google and then actually staying there virtually and asking what feelings, thoughts and memories that place evokes (a Moroccan lady told me when she was on the roof of their family home in Morocco, that she could smell the sand of the Sahara and that this brought her home). Finally, the London transcultural psychiatrists remind us to pay attention to spirituality, psychopathology and aging in different cultures in addition to all this [22]. Aging within immigrant groups in the Netherlands is prominently on the agenda, aging might have consequences for the position of Mater- and Father Familias because roles have to be combined due to death. This attention should also include their dependence on trans-language grandchildren who give them access to the "outside world".

\section{Conclusions}

Super-diverse is more than just rhetoric since humans in large western cities are no longer distributed along lines of majority and minority groups in the population. Superdiverse is more than that we care about colours other than 'WHITE', a different religion than Christianity, other headwear than hat and cap and the number of coloured and black people that the Netherlands can accommodate. Superdiverse requires a redesign of our society. This relates to the subjects of education, health care, neighbourhoods, governments, crime, companies and institutions.

This article is about super-diverse healthcare. $23.12 \%$ of the Dutch population comes from a country other than the Netherlands [1]. Large groups of inhabitants of the Netherlands are now Indonesian, Surinamese, Turkish, Moroccan and Polish. The Dutch CBS is concerned about the (physical and mental) health of non-Western immigrants [1]. In this article a proposal is made for the reorganization of somatic- and psychological healthcare that does justice to the Randstad (8.219 million, 2016) in the Netherlands as a super-diverse society. Connection is sought with existing legislation, multilingualism is promoted and the alarm bell sounds about the increasing number of trans-language children. English, European, Dutch and American guidelines are used to develop health guidelines that go beyond crosscultural and intercultural communication, an important but overvalued topic. The crux of the healthcare guidelines for super-diverse health care is anchored in the conceptual system developed in holism [2]. After all, in the Caribbean, South America, Africa and Asia, people are connected to the greater whole, the nuclear and extended family members, the deceased, the children not yet born, the spirits, God, nature and cosmos. Africa, for example, has the concept of Ubuntu for that, meaning "I am there because we are there". India uses representation of all these connections in the human body through seven juices (from Hinduism). This insight, this connectedness, has consequences for the approach to health care. Psychologists and psychiatrists have developed Cultural Concepts of Distress for this. Although useful, caution is required with these concepts. These concepts are also referred to as neo-colonization by psychiatry. In these health guidelines, we try to transcend this through disease story traditions that can result in a cultural explanation for the disease of the large family, tribe, and community to which the "sick" is connected.

The material in question is not a terminus, concepts and approaches are under development and also receive help from neurology, because established somatic insights such as smell and touch are culturally determined. Important practical developments in the western world can be found in England (Professor Dr. Kamaldeep Bhui has set up a Cultural Consultation Centre in London), in Canada (where a lot of research is being conducted by McGill University in the group of Professor Dr. Laurence J. Kirmayer who is also experimenting with methods like ethno-psychoanalysis where professional caregivers and healers collaborate) and France where French psychiatrist Marie Rose Moro has traditionally devoted a great deal of attention to the system approach and thus the involvement of the extended family in the treatment.

\section{References}

[1] CBS (2018). Jaarrapport Integratie 2018. Centraal Bureau voor de Statistiek. Henri Faasdreef 312, 2492 JP Den Haag. Retrieved from www.cbs.nl.

[2] Ramose, Mogobe (2018). Ubuntu. Stroom van het bestaan als levensfilosofie. Ten Have.

[3] Tutu, Desond \& Tutu, Mpho (2014). The book of forgiving. The fourfold path for healing ourselves and our world. William Collins.

[4] Rafighi, Elham, Poduval, Shoba, Legido-Quigley, Helena and Howard, Natasha (2016). National Health Service Principles as Experienced by Vulnerable London Migrants in "Austerity Britain": A Qualitative Study of Rights, Entitlements, and Civil-Society Advocacy. Int J Health Policy Management 2016, 5 (10), 589-597. 10.15171/ijhpm.2016.50. 
[5] Steinmetz (2018). Verward gedrag en een niet-Nederlandse afkomst. Aanknopingspunten voor preventie. Sociaalbestek december 2018. DOI: 10.1007/s41196-018-0167-7.

[6] Rillof, Pascal and Buysse, Lieven (2015). Getting organized to beat Babel in multilingual service encounters: The European Network for Public Service Interpreting and Translation (ENPSIT). The International Journal for Translation \& Interpreting Research. trans-int.org. DOI: 10.12807/ti.107203.2015.a13.

[7] Ghorashi, Halleh (2016). Wat als iedereen immigrant zou zijn? Deze column is uitgesproken als onderdeel van een duooptreden met Marli Huijer (Denker des Vaderlands) tijdens de Filosofie Nacht, op 15 april 2016 in Amsterdam. Retrieved from: https://www.kis.nl/blog/wat-als-iedereen-migrant-zouzijn.

[8] Alsan, Marcella, Garrick, Owen, and Graziani. Grant C. (2019). Does Diversity Matter for Health? Experimental Evidence from Oakland. NBER Working Paper No. 24787 , June 2018, Revised May 2019, JEL No. C93, I12, I14. A data appendix is available at http://www.nber.org/dataappendix/w24787. A randomized controlled trials registry entry is available at:

https://www.socialscienceregistry.org/trials/2497

[9] Van der Ven, Els (2015). Ethnic minority position as risk indicator for autism-spectrum and psychotic disorders. Doctoral Dissertation Maastricht.

[10] Huijnk, Willem (2018). De religieuze beleving van Moslims in Nederland. Sociaal Cultureel Planbureau. SCP-publicatie 2018-11.

[11] Majida, Asifa, Robertsc, Seán G., Cilissena, Ludy, Emmoreyd, Karen, Nicodemuse Brenda, O'Gradyd, Lucinda, Wollf, Bencie, LeLang, Barbara, de Sousaa, Hilário, Canslerh, Brian L., Shayani, Shakila, Vosa, Connie de, Senfta, Gunter, Enfieldj, N. J., Razakk, Rogayah, Feddenl A., Sebastian, Tufvessona, Sylvia, Dingemansea, Mark, and Ozturkm, Ozge, Browna, Penelope, Hilla, Clair, Le Gueno, Olivier, Hirtzelp, Vincent, van Gijnq, Rik,. Sicolir, Mark A, and Levinsona, Stephen C., (2018). Differential coding of perception in the world's languages. PNAS | November 6, 2018 | vol. 115 | no. 45 | 11369-11376.

[12] Bruijn, de, Ellen (2018). Makkelijk praten over smaak. NRC, 5 december 2018.
[13] Streit, Ursula, Leblanc, Jean, and Mekki-Berrada, Abdelwhahed (1998). A Maroccan Woman suffering from depression: migration as an attempt to escape sorcellerie. Culture, Medicine and Psychiatry 22: 445-463, 1998. (C) 1998 Kluwer Academic Publishers. Printed in the Netherlands.

[14] Scherder, Erik, Os, van, Carla, en Zijlstra, Elianne (2018). Schaderisico bij uitzetting langdurig verblijvende kinderen. Een multidisciplinaire wetenschappelijke onderbouwing. Rijksuniversiteit Groningen en Vrije Universiteit Amsterdam. https://www.rug.nl/research/portal/nl/publications/schaderisic o-bij-uitzetting-langdurig-verblijvende-kinderen (155dea050b98-4aca-a950-d1f20a3d4ad0).html

[15] Bhui Kamaldeep S., Owiti John A., Palinski Andrea, Ascoli Micol, Jongh de Betine, Archer Jane, Staples Pat, Ahmed Nilu, \& Ajaz Ali (2015). A cultural consultation service in East London: Experiences and outcomes from implementation of an innovative service. International Review of Psychiatry, February, 2015; 27 (1): 11-22.

[16] Stevens, Flannery, Plaut, Victoria C. and Sanchez-Burks, Jeffrey (2008). Unlocking the benefits of diversity: allinclusive multiculturalism and Positive Organisational Change. The Journal of Applied Behavioural Science, Vol. 44 No. 1, March 2008 116-133.

[17] Suurmond, Jeanine, Seeleman, Conny, Stronks, Karien en Essink-Bot, Marie-Louise (2012). Een arts van de wereld. Etnische diversiteit in de medische praktijk. Tweede herziene druk. Bohn Stafleu van Loghum.

[18] Jong, de, Joop en Colijn, Sjoerd 92010). Handboek Culturele psychiatrie en psychotherapie. De Tijdstroom.

[19] American Psychological Association (2017). Multicultural Guidelines: An Ecological Approach to Context, Identity, and Intersectionality. Retrieved from: http://www.apa.org/about/policy/multicultural-guidelines.pdf

[20] Steinmetz, Carl H. D. (2019). Stresstalen: werken met ziekteverhalen uit niet-westerse landen. Uitgeverij SWP. Wordt gepubliceerd in September 2019.

[21] Lago, Colin. editor (2011). The handbook of Transcultural Counselling and Psychotherapy. McGrawHill. Open University Press.

[22] Bhugra, Dinesh and Bhui, Kamaldeep (2007). Textbook of Cultural Psychiatry. Cambridge University Press, Medicine. 